\section{Pneumatic retinopexy: new breaks for old?}

The earliest use of an intraocular air injection in the treatment of retinal detachment has been attributed to $\mathrm{Ohm}$ in $1911,{ }^{1}$ but it was not until after Gonin had described the importance of identification and closure of retinal breaks that Rosengren $^{2}$ introduced the concept of air as an internal tamponade specifically for this objective using a drain-air-diathermy surgical sequence.

The introduction ${ }^{3}$ and subsequent refinement ${ }^{4}$ of scleral buckles in the management of retinal detachment reduced the popularity of intravitreal air or gas injections in the era of 'non-drainage' surgery until the two were combined effectively for selected retinal detachments where break localisation and closure were less predictable. ${ }^{5}$

The introduction of relatively insoluble gases enabled Hilton ${ }^{6,7}$ to modify Rosengren's technique and introduced gas into the vitreous cavity without the requirement for release of subretinal fluid, gas expansion and closure of the retinal break with consequent retinal reattachment being followed by retinopexy. The potential advantages of office-based outpatient retinal detachment repair are obvious and attractive and are reflected in the growing popularity of this technique in the USA. ${ }^{8}$

The importance of strict patient selection criteria was emphasised in Hilton's original report ${ }^{7}$ of an $84 \%$ single-operation success. Pneumatic retinopexy was restricted to those patients with superior detachments, absent PVR and single or adjacent breaks. Even with these constraints a large, well-conducted, multicentre randomised prospective study by experienced vitreoretinal surgeons reported a singleoperation failure rate of $27 \%$ for pneumatic retinopexy compared with an $18 \%$ failure rate for the group randomised to scleral buckling surgery. ${ }^{9}$ Most of the patients randomised to scleral buckle surgery had circumferential explants, frequently combined with drainage, so that it was not possible to analyse the potential benefits of radially orientated explants. ${ }^{10}$

More recent studies have reported a primary failure rate of $30-40 \%$ for pneumatic retinopexy ${ }^{11,12}$ and a common theme is that redetachment occurs almost exclusively within the first month, late failures (after 6 months) being unusual. ${ }^{13,14}$ These figures are reflected and confirmed in the current series reported by Assi $e t$ al. in this issue. ${ }^{15}$ The authors are experienced retinal surgeons and the relatively small number of patients recruited from two major hospitals over a 3 year period gives an indication of the restricted patient selection. The convenience and cost-effectiveness of pneumatic retinopexy need to be taken in context. All patients enrolled in the study had a localised detachment with single or closely grouped tears and yet, even in experienced hands, inoperable retinal detachment was the final result for two patients.

Undoubtedly some, if not most, of the failures with this technique are accounted for by breaks missed at the primary procedure and in this respect the lack of opportunity for a careful and thorough examination under anaesthesia is likely to be an important factor. Nevertheless, new breaks undoubtedly do occur ${ }^{13,16}$ and it is interesting to speculate why the technique of pneumatic retinopexy should be so prone to this complication. The majority of studies on pneumatic retinopexy have by inference recruited patients with horseshoe tears associated with posterior vitreous detachment, but this is rarely specified and the present study is no exception. Others have reported their experience using pneumatic retinopexy with dialyses or giant tears where the factors contributing to failure may be very different. ${ }^{17,18}$ The presence or otherwise of a posterior vitreous detachment and its relationship to the intraocular gas injected can be a significant factor influencing new tear formation. Fig. 1 illustrates a patient with an inferior recurrent retinal detachment secondary to gas expansion behind, rather than in front of, the posterior hyaloid membrane. This resulted in the opening of an inferior horseshoe tear (not shown). Migration and subsequent expansion of a gas bubble into the retro-hyaloid (pre-retinal) space is of particular risk when both a posterior vitreous detachment has occurred and the initial volume of gas introduced is small (typically $0.3 \mathrm{ml}) .{ }^{19}$ If the break is large, the gas may even enter the subretinal space ${ }^{20}$ and it is safer to flatten the retina completely in a controlled fashion, prior to the introduction of the gas tamponade either by vitrectomy or the D-ACE surgical sequence according to preference.

If, as Assi and colleagues have indicated, a further study is to be worthwhile it would be important to avoid replication of the wellconstructed multicentre pneumatic retinopexy
Martin Snead Vitreoretinal Service Addenbrooke's NHS Trust Hills Road

Cambridge CB2 2QQ, UK e-mail: mps34@cam.ac.uk 


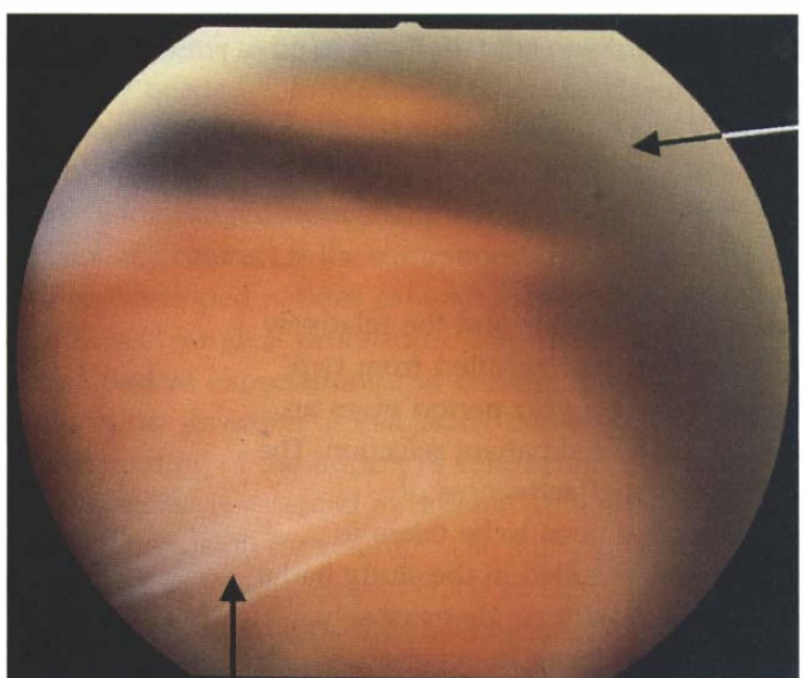

Fig. 1. An inferior recurrent retinal detachment secondary to gas expansion behind, rather than in front of, the posterior hyaloid membrane. Upper arrow, gas bubble behind the posterior hyaloid membrane; lower arrow, shortened and elevated posterior hyaloid membrane.

trial and particularly to attempt to resolve the issue of failure being secondary to either a missed or a new retinal break. The proportion of failures being genuinely due to a missed primary break is only likely to be resolved satisfactorily if the conditions for examination are equally advantageous for both the pneumatic retinopexy and scleral buckling arms of the study. In the clinic setting, adequate scleral depression may be compromised for many reasons. At least for the purposes of such a prospective study, consideration ought to be given to randomising patients to pneumatic retinopexy or scleral buckling surgery at the time of surgery and only after examination under anaesthesia. For those cases of early recurrence with new breaks, clearer data relating to type of break, presence or otherwise of a posterior vitreous detachment and the relationship of the gas tamponade to the posterior hyaloid membrane are required.

\section{References}

1. Ohm J. Über die Behandlung der Netzhautablosung durch operative Entkeering der subretinalen Flussigkeit und Einspritzung von Luft in den Glaskorper. Graefes Arch Klin Ophthalmol 1911;79:442-50.

2. Rosengren B. Über di Behandlung der Netzhautablosung mittelst Diathermie und Luftinjektion in den Glaskorper. Acta Ophthalmol 1938;16:3-42.
3. Custodis E. Scleral buckling without excision and with polyviol implant. In: Schepens CL, editor. Importance of the vitreous body in retina surgery with special emphasis on reoperations. St Louis: CV Mosby, 1960.

4. Lincoff HA, Baras I, McLean J. Modifications to the Custodis procedure for retinal detachment. Arch Ophthalmol 1965;73:160-3.

5. Chawla HB, Coleiro JA. Retinal detachment treated with intravitreal air: an evaluation of 241 cases. Br J Ophthalmol 1977;61:588-92.

6. Hilton GF, Grizzard WS. Pneumatic retinopexy: a two step outpatient operation without conjunctival incision. Ophthalmology 1986;93:626-41.

7. Hilton GF, Kelly NE, Salzano TC, Tornambe P, Wells JW, Wendel RT. Pneumatic retinopexy: a collaborative report of the first 100 cases. Ophthalmology 1987;94:307-14.

8. Benson WE, Chan P, Sharma S, Snyder WB, Bloome MA, Birch DG. Current popularity of pneumatic retinopexy. Retina 1999;19:238-41.

9. Tornambe PE, Hilton GF. The retinal detachment study group: pneumatic retinopexy. A multicenter randomised controlled trial comparing pneumatic retinopexy with scleral buckling. Ophthalmology 1989;96:772-84.

10. Lincoff H. Discussion. Ophthalmology 1989;96:784.

11. Han DH, Mohsin NC, Guse CE, Hartz A, Tarkanian CN, and the southeastern Wisconsin pneumatic retinopexy study group. Comparison of pneumatic retinopexy and scleral buckling in the management of primary rhegmatogenous retinal detachment. Am J Ophthalmol 1998;126:658-68.

12. Grizzard WS, Hilton GF, Hammer ME, Taren D, Brinton DA. Pneumatic retinopexy failures. Ophthalmology 1995;102:929-36.

13. Poliner LS, Grand MG, Schoch LH, Olk RJ, Johnson GP, Okun E, et al. New retinal detachment after pneumatic retinopexy. Ophthalmology 1987;94:315-8.

14. Tornambe PE, Hilton GF, Brinton DA, Flood TP, Green S Grizzard WS, et al. Pneumatic retinopexy: a two year follow up of the multicentre clinical trial comparing pneumatic retinopexy with scleral buckling. Ophthalmology 1991;98:1115-23.

15. Assi AC, Charteris DG, Pearson RV, Gregor ZJ. Pneumatic retinopexy in the treatment of primary rhegmatogenous retinal detachment. Eye 1999;13:00-00.

16. Freeman WR, Lipson BK, Morgan CM, Liggett PE. New posteriorly located breaks after pneumatic retinopexy. Ophthalmology 1988;95:14-8.

17. Irvine AR, Lahey JM. Pneumatic retinopexy for giant retinal tears. Ophthalmology 1994;101:524-8.

18. Melgen SE, Michels M. Pneumatic retinopexy for the treatment of giant dialyses. Am J Ophthalmol 1994;118:762-5.

19. Herbert EN, Snead MP. The importance of injection rate in achieving a single intraocular gas bubble. Eye 1997;11:571-2.

20. McDonald RH, Abrams GW, Irvine AR, Sipperley JO, Boyden BS, Fiore JV, et al. The management of subretinal gas following attempted pneumatic retinal reattachment. Ophthalmology 1987;94:319-26. 